University of Rhode Island

DigitalCommons@URI

Open Access Master's Theses

2016

\title{
A Study of the Increased Risk of Bleeding Events in Patients with Blood Clotting Disorders, Associated with Antidepressant Medication Use
}

Adam Ehrenborg

University of Rhode Island, adam_ehrenborg@my.uri.edu

Follow this and additional works at: https://digitalcommons.uri.edu/theses

\section{Recommended Citation}

Ehrenborg, Adam, "A Study of the Increased Risk of Bleeding Events in Patients with Blood Clotting Disorders, Associated with Antidepressant Medication Use" (2016). Open Access Master's Theses. Paper 840.

https://digitalcommons.uri.edu/theses/840

This Thesis is brought to you for free and open access by DigitalCommons@URI. It has been accepted for inclusion in Open Access Master's Theses by an authorized administrator of DigitalCommons@URI. For more information, please contact digitalcommons-group@uri.edu. 
A STUDY OF THE INCREASED RISK OF BLEEDING EVENTS IN PATIENTS WITH BLOOD CLOTTING DISORDERS, ASSOCIATED WITH ANTIDEPRESSANT MEDICATION USE BY

ADAM EHRENBORG

A THESIS SUBMITTED IN PARTIAL FULFILLMENT OF THE REQUIREMENTS FOR THE DEGREE OF MASTER OF SCIENCE

IN

PHARMACEUTICAL SCIENCES

UNIVERSITY OF RHODE ISLAND

2016 


\title{
MASTER OF SCIENCE THESIS
}

OF

\section{ADAM EHRENBORG}

THESIS COMMITTEE:

MAJOR PROFESSOR: Stephen Kogut

\author{
Aisling Caffrey \\ Bingfang Yan \\ Nasser H. Zawia \\ DEAN OF THE GRADUATE SCHOOL
}

UNIVERSITY OF RHODE ISLAND

2016 


\begin{abstract}
Background: Patients with blood clotting disorders have severely depleted levels of blood clotting factor $(\mathrm{BCF})$ proteins in their blood, which results in a significantly higher risk of bleeding events than a typically healthy patient. Serotonin based antidepressant medications, such as selective serotonin reuptake inhibitors (SSRI) or serotonin norepinephrine reuptake inhibitors (SNRI) alter the levels of serotonin in the blood as a mechanism to treat depression.

Serotonin is used for many different chemical processes within the body including blood aggregation. We sought to quantify the potential risk associated with the use of these types of antidepressant medications to patients with blood clotting disorders.
\end{abstract}

Objective: To determine if patients with BCF disorders who are prescribed SSRI or SNRI medications are at an increased risk of having a major bleeding event.

Methods: A retrospective cohort study was conducted using data from the Optum Clinformatics Data Mart. An initial cohort of 16,124 patients with blood clotting disorders was formed; patients were excluded based upon enrollment eligibility, drug prescription date outside the study timeframe, and age under 12 years. A final study sample of 7,998 patients was formed. A follow up period of six months was selected to analyze major bleeding events; these events were identified using ICD-9 codes for hemorrhages. Patients were classified as to whether a bleeding event occurred during the period. The use of antidepressant medications was determined by prescription drug 
dispensings three months prior to the follow up period. Both univariate and multivariate logistic regression models were built to enhance a final multivariate predictive model.

Results: The use of SSRI and SNRI antidepressant medications was not associated with an increased risk of bleeding events $(\mathrm{p}=0.93)$. Risk factors for having a major bleeding event included older age $(\mathrm{P}=<0.0001)$, male gender $(\mathrm{P}=<0.0001)$, diabetes $(\mathrm{P}=0.0001)$, nonsteroidal anti-inflammatory drug (NSAID) use $(\mathrm{p}=0.0040)$, anticoagulant use $(\mathrm{P}=<0.0001)$, and Hemophilia A ( $\mathrm{p}=0.0001)$. Patients who were between $46-65$ years old were 1.85 times more likely to have a major bleeding event than those between the ages of 26-45 (95\% CI: 1.31-2.61). This risk increases to 3.47 times for those between the ages of 66-90 (95\% CI: 2.36-5.11). Males were 1.84 times more likely to have a major bleeding event in comparison to females (95\% CI: 1.42-2.38). Patients who had diabetes are at 1.84 times the risk of a major bleeding event than those with diabetes $(95 \% \mathrm{CI}$ : 1.35-2.52). Patients with Hemophilia A had approximately twice the risk of experiencing a bleeding event as compared with patients having other blood clotting disorders (OR 2.13; 95\% CI: $1.54-2.93)$.

Conclusion: SSRI and SNRI antidepressant medications were not associated with an increased risk of bleeding events in this study. Factors associated with major bleeding events included male gender, older age, the use of NSAIDs or anticoagulants, and a diagnosis of Hemophilia A. 


\section{ACKNOWLEDGMENTS}

I would like to thank my major professor, Dr. Kogut for his guidance throughout my Bachelors and Master's programs. Dr. Kogut's mentorship aided in the preparation of my proposal and thesis, helping ensure deadlines were met on-time and with the best possible presentation. I have obtained crucial skills and methods from Dr. Kogut's numerous pharmacoeconomics and health systems courses.

I would also like to acknowledge my thesis committee to their time and support throughout the thesis process. Dr. Caffrey's classes on epidemiology was pivotal in my ability to properly design and analyze this research study. I would also like to thank Dr. Yan for his guidance throughout my academic career at URI.

Finally, I would like to thank my parents Kathy and Michael and my sister Jessi for their endless support, encouragement, and sacrifice giving me the ability to complete not only my bachelor's degree, but also a master's degree. 


\section{TABLE OF CONTENTS}

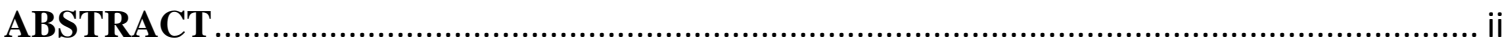

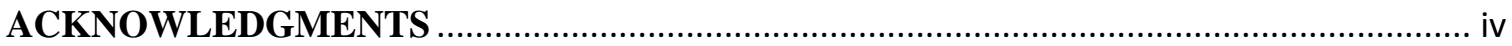

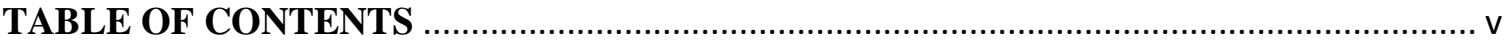

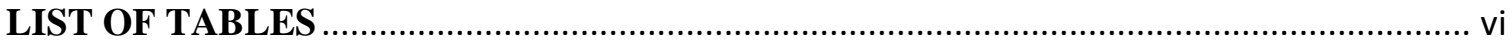

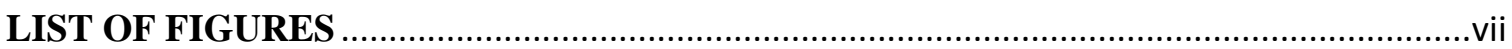

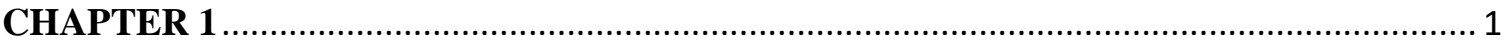

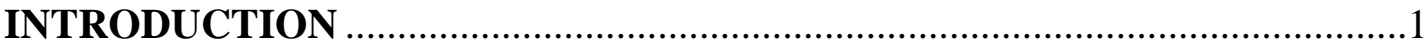

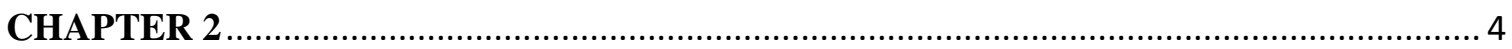

REVIEW OF THE LITERATURE .........................................................

CHAPTER 3

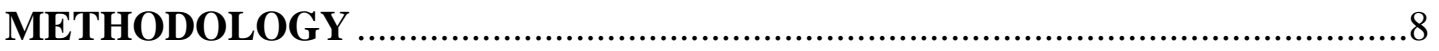

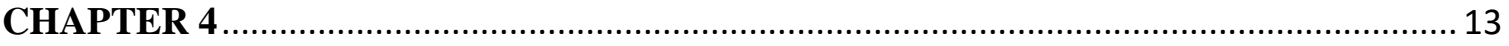

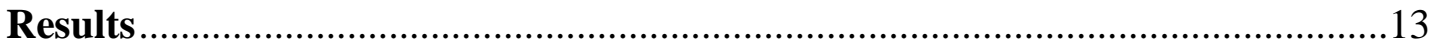

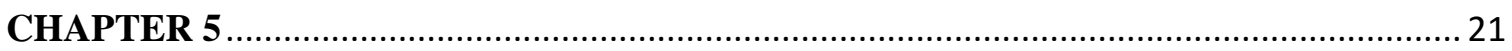

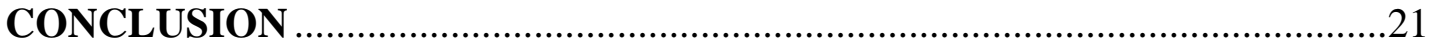

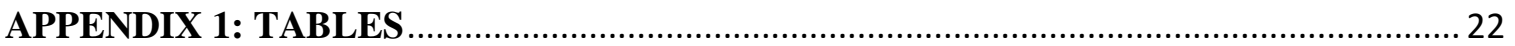

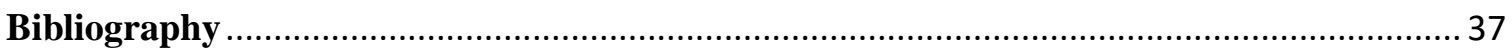




\section{LIST OF TABLES}

Table 1a: Bivariate Analysis: Demographic and Clinical Characteristics of Patients with

Blood Clotting Factor Disorder $(\mathrm{N}=7,998)$

Table 1b: Bivariate Analysis: Bleeding Events versus each type of Blood Clotting Factor

Disorders $(\mathrm{N}=7,998)$

Table 1c: Bivariate Analysis: Demographic and antidepressant exposure characteristics of

Patients with Blood Clotting Factor Disorder $(\mathrm{N}=7,998)$.

Table 2a: Antidepressant Exposure Population, Class distribution $(n=1,531)$

Table 2b: SSRI, SNRI, Modulator Use and Risk of Bleeding Events, Results by Specific

$\operatorname{Drug}(\mathrm{N}=1,531)$

Table 3: Univariate Logistic Regression Analysis of Bleeding Events in Patients with Blood Factor Clotting Disorders, Risk According to Demographics, Clinical

Characteristics and Antidepressant Use.

Table 4: Saturated Logistic Regression Analysis of Bleeding Events in Patients with Blood Clotting Factor Disorders, Risk According to Demographic, Clinical

Characteristics, and Antidepressant Medication Use

Table 5: Multivariate Logistic Regression Analysis with Statistically Significant Variables, For Bleeding Events in Patients with Blood Clotting Factor Disorders, Risk According to Demographic, Clinical Characteristics, and Antidepressant Medication Use . 


\section{LIST OF FIGURES}

APPENDIX 2: Flow Charts

31

Figure 1: Study Sample Selection Flow Chart............................................... 31

Figure 2: All Antidepressant Dispersions .................................................. 32

APPENDIX 3: Diagnosis codes for Blood clotting disorders, hemorrhages, and drug class

codes 33

APPENDIX 4: Identifying bleeding events using ICD-9 codes for Hemorrhages (25) ... 34

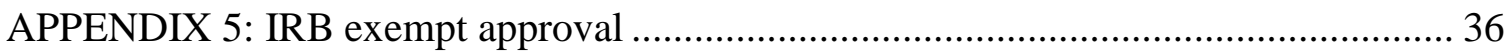




\section{CHAPTER 1}

\section{INTRODUCTION}

Blood Clotting Factor disorders (BCF) are defined as inherited disorders that affect the body's ability to clot blood, thus increasing the frequency and duration of bleeding events. There are 12 different BCF proteins within the human body responsible for blood coagulation. (1) The most common types of BCF disorders are Hemophilia A, Hemophilia B, and Von Willebrand disorder. Hemophilia is an extremely rare disease; there are an estimated 20,000 cases in the U.S. (2) Hemophilia is a life-long disease that is typically diagnosed at an extremely young age either by blood test or by the occurrence of a bleeding event. Von Willebrand disease (VWD) is the most common BCF disorder that affects approximately $1 \%$ of the population. (3) VWD is a genetically inherited deficiency in the clotting protein which binds BCF VIII to the vessel walls. VWD occurs equally in both men and women; hemophilia occurs almost solely in the male population. $(2,3)$ This is due to hemophilia being an X-linked chromosome disease. The male chromosome consists of both an $\mathrm{X}$ and a $\mathrm{Y}$ chromosome while the female chromosome has two X. For a male to inherit hemophilia the trait only has to be present in the mother, while a female would need both the mother and father to have a hemophilia mutation. In most cases females who inherit the hemophilia trait will be a carrier, but they will not exhibit symptoms. (4)

Patients with hemophilia can be categorized based upon their severity of disease. Approximately $60 \%$ of patients with hemophilia are considered to be severe cases having less than $1 \%$ of normal BCF activity, approximately $15 \%$ are moderate cases ranging from $1-5 \%$, and approximately $25 \%$ are mild cases ranging from 5-40\%. (4) Patients with 
severe hemophilia can experience a bleed (minor or major event) once or twice a week, while moderate cases experience a bleed approximately once a month, and mild cases bleed only after surgery or trauma.(4) If left untreated hemophilia can cause serious damage to joints, muscle tissue, and organ tissue as a result of continuous bleeding and swelling.

Antidepressant medications are prescribed for numerous reasons including but not limited to depression, attention-deficit hyperactivity disorder (ADHD), anxiety disorder, and bipolar disorder.(5) It is estimated that approximately one in ten adults in the U.S. are prescribed an antidepressant medication. (6) Due to the burden of disease, the prevalence of depression among patients with hemophilia is approximately 37\%. (7) Selective Serotonin Reuptake Inhibitors (SSRI) and Serotonin-Norepinephrine Reuptake Inhibitors (SNRI) are the most commonly prescribed classes of antidepressants prescribed in the U.S.; in a study using data from the National Ambulatory Medical Care Survey (NAMCS) it was found that $65 \%$ of all antidepressant drugs prescribed in 2000 were SSRI, while newer SNRI drugs accounted for $17 \%$ of the antidepressant utilization. (8) Serotonin based antidepressants can affect the body's ability to clot blood, this may have potential negative repercussions for patients with depleted BCF activity.

SSRI and SNRI drugs impair platelet aggregation by preventing serotonin reabsorption. $(9,10)$ Serotonin is an important neurotransmitter indirectly involved in platelet aggregation. Coated-platelets are rich in collagen, thrombin, and prothrombinase, a serine based protein that activates the proteins responsible for procoagulant activity. (11) Coated-platelets clot a bleed by adhering to the wall of the blood vessel (von Willebrand factor protein produced by the vessel walls), other platelets then crash into the adhered 
platelets and begin to clump together due to the collagen and thrombin. This webbing created by the platelets coated with collagen and thrombin, traps red blood cells as well as other proteins in the blood to create a clot. Reducing the level of serotonin available will diminish the levels of coated-platelets in the blood.

We hypothesize that patients who are prescribed SSRI or SNRI medications will be more likely to experience a major bleeding event than those not using an SSRI or SNRI antidepressant medication. Furthermore, we hypothesize that patients with BCF disorders would be prescribed different classes of antidepressant medications as a result of this increased risk. The objective of this study is to determine if patients with BCF who are prescribed SSRI or SNRI antidepressants are at a higher risk of a major bleeding event occurring. A secondary objective of our study is to describe the prescribing frequency of antidepressant medication classes for patients with BCF disorders. 


\section{CHAPTER 2}

\section{REVIEW OF THE LITERATURE}

Although a literature review of studies comparing bleeding rates for patients with $\mathrm{BCF}$ disorders and the potential impact of antidepressant medication yielded no direct results, there was still enough relevant literature available to help provide a basis for this study.

Von Willebrand's Disease is the most common genetic BCF disorder, found in $0.1-1 \%$ of the population. Within this patient population it is estimated that $10 \%$ of patients display symptoms of the disease. (12) Von Willebrand factor (vWF) is an adhesive glycoprotein responsible for gluing platelets to the vessel wall to form a clot. James et al. (13) identifies some of the major areas of bleeding associated with VWD: mucocutaneous (mucosa/skin transition) and epistaxis (nasal) bleeding, as well as easy and frequent tissue bruising. (13-15) Female patients frequently experience abnormally heavy bleeding during menstruation (menorrhagia). (16) Fressinaud et al. (17) also notes that gastrointestinal (GI) bleeding is reported in approximately 10\% of VWD patients.

Hemophilia is a genetically transmitted disease on the $\mathrm{X}$-chromosome. Both males and females can inherit the disease, but typically only males exhibit symptoms. Females who inherit the mutation for hemophilia are considered carriers and are not symptomatic. Plug et al (18) conducted an analysis of bleeding in carriers of hemophilia compared to those who are non-carriers. The researchers conducted this analysis using self-reported information collected from a survey of 546 women within the Netherlands; of these women, 274 were carriers of either hemophilia A or B. The researchers found that there was a significant increase in bleeding events for patients who were carriers of hemophilia 
when compared to non-carriers. They also reported a statistically significant increase in the duration of bleeding for carriers after a tooth extraction, tonsillectomy, or operation. Carriers were twice as likely (Relative Risk (RR), 2.3: $95 \%$ Confidence Interval (CI), 1.5 to 3.4) to have a bleed lasting longer than three hours after one of these procedures when compared to non-carriers. Hemophilia has an estimated incidence of 1 in 5,000 male births. (2) Soucie et al. (2) conducted a study for the Center for Disease Control and Prevention (CDC) in 1994, estimated that there were approximately 17,000 cases of hemophilia (A and B) in the U.S. Using birth and death rates since that time the CDC estimates that number has risen to approximately 20,000. (2) Males who inherit the hemophilia trait will be symptomatic due to only inheriting the $\mathrm{X}$ chromosome from his carrier mother and the $\mathrm{Y}$ from his father. Males who have hemophilia typically have frequent minor bleeds. Major bleeding events are usually the result of surgery or trauma. For male patients the majority of bleeding events occur internally and can result in serious damage caused to joints, muscle tissue, and organ tissue due to continuous bleeding and swelling. $(2,19)$

A study conducted by Dawson et al (20) using commercial claims data from 2008-2013 was used to obtain a baseline measure for the utilization of each antidepressant drug class among privately insured patients, irrespective of comorbidity. The study population consisted solely of privately insured women age 15-44. The population ranged from 4.6 million to 6.8 million (per year) during the 5 year duration. They found that $15.4 \%$ of women had a prescription for an antidepressant filled at least once a year. Antidepressant drug claims were categorized by class: SSRI, SNRI, Tricyclic antidepressants (TCA), Monoamine oxidase inhibitors (MAOI) and other. It was found that $10.7 \%$ of the study 
population were prescribed a SSRI, $2.8 \%$ were prescribed an SNRI, $1.4 \%$ were prescribed a TCA, 0\% were prescribed a MAOI, and 3.9\% were prescribed other types. They also found that $11.7 \%$ of the population filled a prescription for only one class of antidepressant, while $3.7 \%$ filled prescriptions for multiple classes of antidepressants.

A study by Turner et al. $(9,21,22)$ details how SSRI drugs impact the likelihood of a bleeding event. The authors explain how SSRIs impact platelet aggregation by preventing serotonin from being reabsorbed at a normal rate. The authors concluded that the effect on platelets by SSRI drugs may have a clinical importance when considering a patient's risk of bleeding.

Prodan et al. (11) detailed the clinical background of SSRIs and their impact on coatedplatelets. The authors explain that coated-platelets are rich in prothrombinase, a serine based protein that activates proteins responsible for procoagulant activity. This study found that patients prescribed SSRIs had a statistically significantly lower level of coated-platelets in the blood, with an analysis of variance test which yielded a p-value of 0.046. The study also identified smoking and aspirin use as having a significant impact on coated-platelet levels.

It is estimated that approximately one in ten adults in the United States (US) is prescribed an antidepressant medication, for a range of indications. (6) It is important to note, due to the burden of disease, the prevalence of depression among hemophilia patients is estimated at $37 \%$. Iannone et al. (7) identified three covariates that could have a significant effect on the rate of depression for patients with hemophilia: unemployment 
$(\mathrm{P}=0.01)$, lack of social support $(\mathrm{p}=0.04)$, and occurrences of bleeds per year $(\mathrm{P}=0.06)$. This study determined that the increase in number of bleeding events per year was slightly above the threshold for statistical significance; the study reported a $22 \%$ increase in the odds of depression for every five bleeding episodes (per year). Barlow et al (23) also reported that many hemophilia patients struggle with the physical burden of hemophilia, with symptoms including joint bleeds and co-morbidities due to blood transfusions. The authors discussed how these comorbidities diminish the patient's quality of life by affecting their education, work, and social activities.

This study will provide patients and physicians more knowledge about the effects of SSRI and SNRI antidepressants use for patients with BCF disorders. The aim of this study was to determine if patients who are prescribed a SSRI or SNRI medication are more likely to experience a major bleeding event then those not using an antidepressant medication. The study also determined prescribing frequencies for particular antidepressant medications used in patients with BCF disorders. 


\section{CHAPTER 3}

\section{METHODOLOGY}

\section{Study Population and Design}

This study was conducted as a retrospective cohort study of privately insured U.S. citizens who were continuously enrolled throughout 2012. The study population was selected from the Optum Clinformatics Data Mart. Patients were deemed eligible if they had continuous enrollment during the entire year of 2012. The population included patients with Hemophilia A and B, Von Willebrand's Disease, and other non-specified blood clotting disorders. BCF disorders are typically diagnosed at an extremely young age and persists throughout a patient's lifetime. We formed our cohort to include all patients having any of the International Classification of Diseases (ICD-9) diagnosis codes designating a BCF disorder (286.0 - 286.5) available from 2010 to 2012. Most antidepressant medications are not FDA approved for children under the age of 12. (6) Based upon this information the inclusion criterion for age ranged from 12-100 years old. A sample of 621 patients would be required for a cohort study based upon the following characteristics: alpha $=0.05$, power $=0.8$, incidence $=0.3$, and a relative risk $=1.25$. (24) $\mathrm{By}$ expanding our study from hemophilia A to all BCF disorders we were able surpass the required sample size and yield a study population of 7,998.

\section{Dependent Variable:}

Major bleeding events (hemorrhages) was the dependent variable used for this study. Major bleeding events were identified using a series of ICD-9 codes for hemorrhages validated in a study by Arnason et al (appendix 4). (25) A patient who had one or more documented bleeding event, requiring an inpatient or outpatient visit during a 6 month 
follow-up period (July 1, 2012 - December 31, 2016) were assigned a designation of 1 , whereas if no events occurred a designation of 0 was specified. The data source used in our study captured only bleeding events that were serious enough to require medical attention.

\section{Independent Variables}

SSRI or SNRI antidepressant use was the independent variable of interest. Patients were classified as exposed to these medications if they received at least 1 drug claim for either an SSRI or SNRI antidepressant during the 3 month period (April 1, 2016 - June 30, 2016) preceding the 6 month follow-up period for identifying bleeding events. Patients without an SSRI or SNRI antidepressant drug claim during this 3 month period were categorized as unexposed to these medications. Patients who initiated antidepressant drug therapy after this 3 month period were excluded from the analysis. As antidepressant polytherapy is common, we excluded users of non-SSRI/SNRI medications from our multivariate analyses. To describe antidepressant medication utilization overall, we determined the frequency of use of other antidepressant types including tricyclics, MAOIs, serotonin modulators, and miscellaneous antidepressant drugs (Appendix 3). We also created an independent variable describing the type of BCF disorder documented. BCF types were categorized into four groups: Hemophilia A, Hemophilia B or C, VWD, and other clotting factor/ intrinsic anticoagulants. Approximately $6 \%$ of the sample population had ICD-9 codes for multiple blood clotting disorders; these patients were included in the other clotting factor/ intrinsic anticoagulants group. 


\section{Independent Variables:}

This study also investigated age, gender, geographic region, HIV, HEPC, and diabetes as other variables that may impact the risk of a major bleeding event occurring. Values for age, gender, and geographic region were determined during the three month baseline period. HIV, HEPC, and diabetes status were determined using the available eligibility period preceding the follow-up period. Age was tested as a continuous variable and as a categorical variable for the predictive model; the categorical version of age was used to display the distribution for descriptive statistics. The variable "U.S. state" was used to form geographic regions, i.e. Northeast, Midwest, Southeast, Southwest, and West. (26) There are numerous indications for which antidepressant drugs can be used.

\section{Statistical analysis:}

The analysis was conducted using the occurrence of at least one major bleeding episode as the dependent variable. Descriptive statistics were applied to present the frequency and percent of all variables, stratified by exposure and outcome status. Exposure to an SSRI or SNRI antidepressant was the primary independent variable of analysis in this study. A final logistic regression model was constructed using all variables deemed statistically significant. We excluded patients from the multivariate model who were identified as users of only other classes of antidepressant drugs (i.e. TCA, MAOI, serotonin modulator, or miscellaneous antidepressant). We first created univariate logistic regression models for each independent variable, testing each for a statistically significant relationship with the study outcome of bleeding events. Univariate models with a P-value $<0.20$ were considered eligible for inclusion in the initial multivariate model. This saturated logistic regression model included the variables age (continuous), gender, 
region, HIV, HEPC, diabetes, NSAID or anticoagulants, SSRI/ SNRI use, and BCF disorder type (hemophilia A, Hemophilia B/C, VWD, and other/ multiple BCF disorders). Variables within the model having a P-value $<0.05$ were considered statistically significant for this preliminary model.

To construct a final model we used backwards selection to eliminate variables which were included in model selection due to their statistically significant univariate p-values $(<0.20)$. Several models were tested against the saturated model for their goodness-of-fit; with the intent to simplify a final model, creating the best predictive model possible. The likelihood ratio test (LRT) statistic was used to evaluate the different models created. Using the LRT statistic we concluded which variables should be included in the final model, using the following equation:

-2(LRT initial model - LRT Complex model $)=X$-> Zscore -> Chi Sq P-value

Based upon the Chi-Sq distribution and p-value (corresponding to degrees of freedom), we decided whether a variable should be included or excluded in the final model. The Akaike information criterion (AIC) and Hosmer-Lemeshow test were also applied. A smaller AIC value indicated a stronger model fit, while the Hosmer-Lemeshow uses the Pearson Chi-Sq statistic to assess model fit. A correlation procedure was performed for the 17 variables included in the saturated model. The objective of this correlation analysis was to analyze the variables for collinearity effects. A correlation coefficient of 0 would represent no correlation between the variables, thus they do not vary together. Variance inflation factor (VIF) and tolerance values (TOL) were also analyzed to identify 
multicollinearity among variables. VIF values greater than 10 would identify variables with possible collinearity, while a minimum value for TOL of 0.20 would identify variables with multicollinearity effects.(27) Statistically significant variables were tested by creating new variable interaction terms, and testing models both with and without the new variable. These models were tested against each-other using the $-2 \log L$ equation:

-2(LRT initial model - LRT Complex model) $=$ X -> Zscore -> Chi Sq P-value

If the Chi-Sq value was statistically significant a variable interaction would be identified.

A relative risk $(\mathrm{RR})$ was calculated to evaluate the effect of the variables included in the multivariate logistic regression model with risk of bleeding event, including a $95 \%$ confidence interval of the point estimate. The RR reflects the increase in risk of bleeding associated with a particular variable, and was calculated as the probability of an event occurring in the exposed group (event=1) divided by the probability of an event occurring in the unexposed group.

To analyze the prescribing frequency of all types of antidepressants, dispersions of the six antidepressant classifications available were identified. Based upon the antidepressant classes of interest and univariate analyses we further segmented three of the antidepressant classes down to the drug level, SSRI (6 drugs), SNRI (3 drugs), and serotonin modulators (3 drugs). (Appendix 2) 


\section{CHAPTER 4}

\section{Results}

\section{Study population characteristics}

There were 16,124 patients identified as having a blood clotting factor disorder during the timeframe. Patients who did not have continuous enrollment through 2012 were excluded $(\mathrm{N}=6855)$. We then excluded patients under the age of $12(\mathrm{~N}=304)$, and next excluded patients having a new a prescription for antidepressant medication occurring after the 3 month baseline exposure period $(\mathrm{N}=667)$. After all exclusions were applied the study cohort was reduced to 7,998 patients. We identified 1,531 (19.1\%) patients as being prescribed an antidepressant medication during the 3 month baseline period. Of these 1,531 patients, we identified 876 as having an SSRI dispensing, and 377 who had an SNRI dispensing. Using the ICD9 codes for hemorrhage listed in appendix 4, we identified major bleeding events that occurred between 6/1/12 to $12 / 31 / 12$. A total of 238 patients had at least one major bleeding event, among the 7,998 patients in the study population (3.476\%). Of these 238 patients who had a major bleeding event, $42(3.4 \%)$ were prescribed either an SSRI or SNRI antidepressant medication, while 196 (2.9\%) were not.

The study population's predominant characteristics were $65.15 \%$ female, $40.67 \%$ of patients were between 46-65 years old, $30 \%$ lived in the southeast, $0.79 \%$ of patients had a diagnosis for HIV, $1.68 \%$ of patients had a diagnosis of HEPC, $13.43 \%$ of patients had a diagnosis of diabetes, $20.63 \%$ were prescribed a NSAID, $12.59 \%$ were prescribed an anticoagulant, $16.90 \%$ were prescribed an SSRI or SNRI, while $22.73 \%$ were prescribed an antidepressant of any kind. The prevalence of major bleeding events within the study population was $2.98 \%$. 
The bivariate analyses identified several variables that were associated with major bleeding events: older age $(p=0.0001)$, male gender $(p=0.0001)$, diabetes $(p=0.0001)$, NSAID use ( $\mathrm{p}=0.0004)$, anticoagulant use $(\mathrm{p}=0.0004)$, Hemophilia A ( $\mathrm{p}=0.0004)$, and VWD $(\mathrm{p}=0.0006)$.

Antidepressant drug utilization in this patient population was similar to that of the general population. We found that $876(57.2 \%)$ patients were prescribed an SSRI, $377(24.6 \%)$ patients were prescribed an SNRI, $150(9.8 \%)$ patients were prescribed a TCA, less than 10 were prescribed an MAOI antidepressant, $171(11.2 \%)$ received a serotonin modulator, and $254(16.6 \%)$ patients were prescribed an antidepressant classified as miscellaneous. During the 3 month baseline period 1,265 patients received only one class of antidepressant, 236 patients received 2 different classes of antidepressants, and 31 patients received 3 classes of antidepressant drugs.

The use of SSRI or SNRI antidepressants was more frequent among older patients, females, and patients with diabetes ( $p<0.0001$ for all comparisons). Users of NSAIDs and oral anticoagulants were also more likely to be prescribed SSRI or SNRI antidepressants as compared with patients not receiving NSAIDs or oral anticoagulants ( $p$ $<0.0001)$. Further detail is presented in Table 1c.

\section{Univariate Logistic Regression Models}

In univariate logistic regression analyses we identified variables having a statistically significant association with the occurrence of a major bleeding event (Table 3). In the univariate analysis, there was no significant increase in the occurrence of a bleeding event among patients prescribed an SSRI or SNRI medication $(\mathrm{P}=0.68, \mathrm{RR}=1.09,95 \%$ $\mathrm{CI}=0.74-1.60)$. Univariate analyses were also conducted for age, gender, region, HIV, 
HEPC, diabetes, and drugs known to affect bleeding. Age was tested as both a continuous variable and a categorical variable, and both versions had a statistically significant effect on the risk of bleeding $(\mathrm{p}=<0.0001)$. When analyzing age in categories there was a noticeable increase in risk with advancing age. Using 26 to 45 years old as the reference group, there was no difference in risk when compared to the age group 12 to 25 years old. When comparing patients between the ages of 46-65 years to patients age 26-45 years of age, the RR was 1.75 (CI: 1.23-2.51). For patients between 66 and 91 years of age (reference 26-45 years), the risk of major bleeding was more than 3 times higher (RR 3.40; 95\% CI: 2.27-5.08). A univariate model for patient gender was also tested using female gender as the reference category. This model had a $\mathrm{p}=\mathrm{value}$ of $<0.0001$ and a RR of 1.83 (95\% CI: 1.40-2.40). Based upon this information we can conclude that male patients were at a significantly higher risk of having a major bleeding event as compared with female patients. U.S. regions were also evaluated, but no statistically significant effect was found between different geographic areas. Comorbidities of interest at the beginning of this study were identified as HIV, HEPC, and diabetes. Due to contaminated blood in the 1970's and 1980's many patients who required numerous blood transfusions over time contracted HIV and HEPC. $(28,29)$ This study found no significant increase in the risk of major bleeding events for patients with either disease. The RR for HIV was 1.80 (95\% CI: 0.56-5.80) with a p-value=0.3245, and the relative risk for HEPC was 2.05 (95\% CI: 0.94-4.45; $\mathrm{p}=0.0695$ ). (Table 3) A univariate analysis assessing the influence of diabetes revealed that patients with this disease were at an increased risk of a major bleeding event occurring (RR 1.78; 95\% CI: 1.27-2.49; $\mathrm{p}=0.0007$ ). Lastly, a univariate analysis was conducted analyzing drug classes that are known to increase the risk of bleeding. Users of NSAIDs were 54\% more likely to experience a bleeding event (RR 
1.54; $95 \%$ CI: 1.14-2.08), while users of anticoagulants were twice as likely to experience a bleeding event (RR 2.00; 95\% CI: 1.43-2.78).

Univariate analyses were also conducted to assess bleeding risk according to type of $\mathrm{BCF}$ disorder. We found that patients with Hemophilia A had a RR of 2.03 (95\% CI: 1.522.72, $\mathrm{p}=0.0001)$; patients with Hemophilia $\mathrm{B} / \mathrm{C}$ had a non-significant RR of $0.93(95 \%$ CI: $0.59-1.47, p=0.7661)$, patients with VWD had a non-significant RR of 0.75 (95\% CI: CI: $0.54-1.03, \mathrm{p}=0.0737$ ), and those with other/multiple clotting factors had a RR of 1.12 (95\% CI: 0.86-1.03, $\mathrm{p}=0.4088)$. Based upon these findings we conclude that older age, male gender, diabetes, NSAID use, anticoagulant use, and the presence of HEP-C, Hemophilia A, and VWD met the selection criteria for advancing to the multivariate model analysis.

\section{Multivariate Logistic Regression Modeling}

Two multivariate logistic regression models were constructed, a saturated model and a reduced model which includes statistically significant variables or strata. The saturated model (Table 4) included the variables age, gender, region, HIV, HEPC, diabetes, SSRI or SNRI use, NSAID use, anticoagulant use, Hemophilia A, Hemophilia B/C, VWD, and other/ multiple BCF disorders. Several variables were statistically significant in this model: age, gender, NSAID use, anticoagulant use, and Hemophilia A ( $p<0.05$ for all). Within this model VWD was just above significance $(\mathrm{p}-0.074)$. Next, a reduced model was constructed using the variables determined to be statistically significant from the univariate analyses. This reduced model included nine variables: age, gender, diabetes, Hemophilia A, VWD, NSAID use, HEP-C, SSRI or SNRI use, and anticoagulant use. 
Based upon this model a final model was constructed eliminating non-significant variables using backwards elimination. The final model included age, gender, NSAID use, anticoagulant use, hemophilia A, VWD, and SSRI or SNRI use, as risk factors for the occurrence of a major bleeding event. Based upon this final model we can conclude that the risk of a major bleeding event was higher for males, the older population, those patients prescribed NSAID or anticoagulant medications, and patients who had Hemophilia A or VWD.

\section{Discussion}

BCF disorders are complex diseases to live with; patients must deal with sporadic bleeding under normal conditions. Serotonin-based antidepressant medications lower levels of serotonin in the blood, a necessary component in blood coagulation. Any association between serotonin-based antidepressants and bleeding events would be a relevant concern for BCF disorder patients and their physicians.

The results of our analyses revealed that age, gender, NSAID use, anticoagulant use, and Hemophilia A were risk factors in major bleeding. This information coincides with the results of other research available. Studies have revealed that as patients get older they are at a significantly higher risk of bleeding events. (30-32) The risk of major bleeding events due to NSAID use likely varies by patient as well as the duration of on NSAID therapy. A 16 week study found that there was no increased risk of bleeding events for a hemophilic taking $1600 \mathrm{mg}$ of ibuprofen daily. (30) A study assessing upper gastrointestinal bleeding in hemophiliacs found that patients taking an NSAID (naproxen, 
ibuprofen, or diclofenac) for less than one month were at a statistically significant increased risk of GI bleeding. They also reported that patients with prolonged NSAID use (>1 month) were not at an increased risk of bleeding. The researchers further reported that Cox-2-inhibitors (Rofecoxib and Celecoxib) are a safer alternative to NSAIDs for hemophiliac patients. (31) There is little information known about the risk of bleeding in BCF patients taking anticoagulants. Our study results correspond to the known risks of anticoagulants in the general population. (33) Additionally, we tested two-way variable interactions but did not identify any interaction effects between the variables included in our study.

We did not identify an association between SSRI or SNRI use and major bleeding events in our study; although other studies have shown that there is a moderate increase in particular types of bleeding among patients using these drugs. Castro et al. (34) found that patients who used antidepressant medications that have a high affinity for serotonin transporters had an increase in the likelihood of gastrointestinal bleeding. A metaanalysis conducted by Hackam et al. (35) found an association between SSRI use and intracranial hemorrhages (adjusted RR: 1.51; 95\% CI: 1.26-1.81). Their analysis also found an association between SSRI use and intracerebral hemorrhages (adjusted RR: 1.68; 95\% CI: 1.46-1.91), and an increase in risk in patients who were taking both SSRIs and anticoagulants (RR 1.61; 95\% CI: 1.04-2.51).

\section{Strengths and Limitations:}

Due in part to the rarity of hemophilia and other bleeding disorders, there exists little information published about antidepressant use in the hemophilia population. This study 
provides only a preliminary investigation of the risk associated with antidepressant use among patients with BCF disorders using a retrospective cohort design. Further study examining particular SSRI and SNRI medication products and hemorrhage types may reveal increases in bleeding risk that were not evident in our aggregate analyses. Our analysis highlighted age, gender, and NSAID/ anticoagulant use as key risk factors for the occurrence of bleeding events. This study also provides descriptive statistics detailing the antidepressant medication classes used among this sample of patients having a BCF disorder, finding that SSRI and SNRI medications were commonly prescribed.

There were limitations of this study to be noted. The primary limitation of this study relates to data source, which was collected by a national health insurance company, and is based upon individual patient healthcare claims. We were only able to capture episodes of bleeding that that were serious enough to require medical care. Other limitations of claims data include a lack of detail about the event (intensity and outcomes), lack of patient history and demographics, and pharmacy claims do not indicate if the patient actually ingested the drug. Claims data also lack information about the patient's severity of disease and bleeding treatment course (prophylactic or acute treatment).

The sample sizes for users of the antidepressant medications fluvoxamine, olanzapine/ fluoxetine, venlafaxine, and nefazodone were all less than or equal to 10 total patients. In these instances it was possible that no bleeding events occurred because the sample size was so small. Another limitation to this study is the inability to identify major bleeding events as being related to antidepressant use, and not as a result of some other factor. We 
may have also failed to identify patients having diseases such as diabetes, HIV and HEPC if no recent claim associated with these conditions was submitted.

Bleeding events were recorded as either the patient had at least one bleeding event requiring medical attention, or they did not. We did not ascertain the frequency of bleeding events per patient. We were also unable to identify bleeding events due to trauma or illness. Lastly, the generalizability of this study population may not extend to all patients with BCF disorders beyond the commercially insured. These results should not be generalized to programs such as Medicaid or Medicare.

Further research using data collected at hemophilia treatment centers or questionnaires from patients may be able to capture less severe bleeding events. It would also be worth investigating the association between antidepressant use and the duration of bleeding events. Being able to expand the type and number of bleeding events that occur may add further insight into a potential association between antidepressant use and bleeding events in the BCF disorder population. 


\section{CHAPTER 5}

\section{CONCLUSION}

Serotonin based antidepressant medications are known to alter the serotonin levels within the blood. Altering serotonin levels reduce the concentration of coated-platelets within the blood responsible for blood clotting. There is little known information on the association between antidepressant use and episodes of major bleeding in patients with blood clotting factor disorders.

This study did not identify an association between the use SSRI or SNRI antidepressant medications and an increase in the occurrence of major bleeding events. Other important risk factors for major bleeding that were identified in our study included advancing patient age, male gender, and the use of NSAIDs and oral anticoagulants. 


\section{APPENDIX 1: TABLES}

Table 1a: Demographic and Clinical Characteristics of Patients with Blood Clotting Factor Disorders and Association with the Occurrence of a Bleeding Event $(\mathrm{N}=7,998)$

\begin{tabular}{|c|c|c|c|}
\hline & No Bleeding Event & $\begin{array}{c}\text { At least } 1 \\
\text { Bleeding } \\
\text { Event }\end{array}$ & $\begin{array}{l}\text { Chi-Sq } \\
\text { P-Value }\end{array}$ \\
\hline $\begin{array}{l}\text { Cohort } \\
\text { Population }\end{array}$ & $7760(97 \%)$ & $238(3 \%)$ & \\
\hline Age & & & $<0.0001$ \\
\hline $12-25$ Years old & $1,116(98.20 \%)$ & $20(1.80 \%)$ & \\
\hline 26-45 Years old & $2,563(98.16 \%)$ & $48(1.84 \%)$ & \\
\hline 46-65 Years old & $3,144(96.64 \%)$ & $109(3.35 \%)$ & \\
\hline 66-91 Years old & $937(93.89 \%)$ & $61(6.11 \%)$ & \\
\hline Gender & & & $<0.0001$ \\
\hline Female & $5090(97.68 \%)$ & $121(2.32 \%)$ & \\
\hline Male & $2670(95.80 \%)$ & $117(4.20 \%)$ & \\
\hline Region & & & 0.9390 \\
\hline Northeast & $1,288(97.21 \%)$ & $37(2.79 \%)$ & \\
\hline Southeast & 2,322 (96.79\%) & $77(3.21 \%)$ & \\
\hline Midwest & $2,039(97.10 \%)$ & $61(2.90 \%)$ & \\
\hline West & $1,083(97.22 \%)$ & $31(2.78 \%)$ & \\
\hline Southwest & $1,027(96.98 \%)$ & $32(3.02 \%)$ & \\
\hline HIV & & & 0.4367 \\
\hline Yes & 60 & $<5$ & \\
\hline HEPC & & & 0.1225 \\
\hline Yes & $127(94.78 \%)$ & $7(5.22 \%)$ & \\
\hline Diabetes & & & 0.0001 \\
\hline Yes & $1,022(95.16 \%)$ & $52(4.84 \%)$ & \\
\hline NSAID Use & & & 0.0004 \\
\hline Yes & $1,579(95.70 \%)$ & $71(4.30 \%)$ & \\
\hline Anticoagulant Use & & & 0.0004 \\
\hline Yes & $959(95.23 \%)$ & $48(4.77 \%)$ & \\
\hline SSRI & & & 0.8440 \\
\hline Yes & $849(96.92 \%)$ & $27(3.08 \%)$ & \\
\hline SNRI & & & 0.0726 \\
\hline Yes & $360(95.49 \%)$ & $17(4.51 \%)$ & \\
\hline
\end{tabular}


Table 1b: Occurrence of a Bleeding Event by Type of Blood Clotting Factor Disorder $(\mathrm{N}=7,998)$

\begin{tabular}{|c|c|c|c|}
\hline & No Event & Bleeding Event & P-value \\
\hline Hemophilia A & & & 0.0004 \\
\hline Yes & $966(95.64 \%)$ & $44(4.36 \%)$ & \\
\hline Hemophilia B/ C & & & 0.7668 \\
\hline Yes & $587(97.02 \%)$ & $18(2.98 \%)$ & \\
\hline VWD & & & 0.0006 \\
\hline Yes & $1,786(98.13 \%)$ & $34(1.87 \%)$ & \\
\hline $\begin{array}{l}\text { Other Clotting Factors/ } \\
\text { Intrinsic Anticoagulants }\end{array}$ & & & 0.4088 \\
\hline Yes & $4,421(96.89 \%)$ & $142(3.11 \%)$ & \\
\hline
\end{tabular}


Table 1c: Exposure to SSRI or SNRI Antidepressants by Patient Characteristic $(\mathrm{N}=7,998)$

\begin{tabular}{|c|c|c|c|}
\hline & $\begin{array}{l}\text { No Exposure to } \\
\text { SSRI or SNRI }\end{array}$ & $\begin{array}{l}\text { Exposure to } \\
\text { SSRI or SNRI }\end{array}$ & P-Value \\
\hline \multicolumn{4}{|l|}{ Cohort Population } \\
\hline Age & & & $<0.0001$ \\
\hline 12-25 Years old & $1,050(92.40 \%)$ & $86(7.60 \%)$ & \\
\hline 26-45 Years old & $2,239(85.75 \%)$ & $372(14.25 \%)$ & \\
\hline 46-65 Years old & $2,658(81.71 \%)$ & $595(18.29 \%)$ & \\
\hline 66-91 Years old & $813(82.87 \%)$ & $168(17.13 \%)$ & \\
\hline Gender & & & $<0.0001$ \\
\hline Female & $4,246(81.48 \%)$ & $965(18.52 \%)$ & \\
\hline Male & $2,527(90.67 \%)$ & $260(9.33 \%)$ & \\
\hline Region & & & 0.4986 \\
\hline Northeast & $1,161(87.62 \%)$ & $164(12.38 \%)$ & \\
\hline Southeast & $2,002(83.41 \%)$ & $398(16.59 \%)$ & \\
\hline Midwest & $1,755(83.57 \%)$ & $345(16.43 \%)$ & \\
\hline West & $953(85.55 \%)$ & $161(14.45 \%)$ & \\
\hline Southwest & $902(85.17 \%)$ & $157(14.83 \%)$ & \\
\hline HIV & & & 0.0567 \\
\hline Yes & 59 & $>5$ & \\
\hline HEP-C & & & 0.9002 \\
\hline Yes & $114(85.07 \%)$ & $20(14.93 \%)$ & \\
\hline Diabetes & & & $<0.0001$ \\
\hline Yes & $852(79.33 \%)$ & $222(20.67 \%)$ & \\
\hline NSAID Use & & & $<0.0001$ \\
\hline Yes & $1,333(80.79 \%)$ & $317(19.21 \%)$ & \\
\hline Anticoagulant Use & & & $<0.0001$ \\
\hline Yes & $782(77.66 \%)$ & $225(22.34 \%)$ & \\
\hline
\end{tabular}


Table 2a: Frequency of Antidepressant Use by Drug Class $(n=1,531)$

\begin{tabular}{l|lr|}
\hline Antidepressant Class & Number of Patients (\%) \\
SSRI & $876(57.2 \%)$ \\
SNRI & $377(24.6 \%)$ \\
TCA & $150(9.8 \%)$ \\
MAOI & $<5$ \\
Serotonin Modulator & $171(11.2 \%)$ \\
\hline Miscellaneous ratients can be represented in multiple classes due to combination therapy
\end{tabular}


Table 2b: Frequency of a Bleeding Event by Antidepressant Medication Type $(\mathrm{N}=1,531)$

\begin{tabular}{|c|c|}
\hline Drug & $\begin{array}{c}\text { Patients experiencing a } \\
\text { bleeding event } \mathrm{n}(\%)\end{array}$ \\
\hline \multicolumn{2}{|l|}{ SSRI } \\
\hline \multicolumn{2}{|l|}{ Citalopram } \\
\hline Yes & $253(16.5 \%)$ \\
\hline \multicolumn{2}{|l|}{ Escitalopram } \\
\hline Yes & $166(10.8 \%)$ \\
\hline \multicolumn{2}{|l|}{ fluoxetine } \\
\hline Yes & $154(10.0 \%)$ \\
\hline \multicolumn{2}{|l|}{ Fluvoxamine } \\
\hline Yes & $6(0.4 \%)$ \\
\hline \multicolumn{2}{|l|}{ Paroxetine } \\
\hline Yes & $63(4.1 \%)$ \\
\hline \multicolumn{2}{|l|}{ Sertraline } \\
\hline Yes & $261(17.0 \%)$ \\
\hline \multicolumn{2}{|l|}{ SNRI } \\
\hline \multicolumn{2}{|l|}{ Duloxetine } \\
\hline Yes & $176(11.5 \%)$ \\
\hline \multicolumn{2}{|c|}{ Desvenlafaxine } \\
\hline Yes & $48(3.1 \%)$ \\
\hline \multicolumn{2}{|l|}{ Venlafaxine } \\
\hline Yes & $156(10.2 \%)$ \\
\hline \multicolumn{2}{|l|}{ Modulators } \\
\hline \multicolumn{2}{|l|}{ Nefazodone } \\
\hline Yes & $<5$ \\
\hline \multicolumn{2}{|l|}{ Trazodone } \\
\hline Yes & $156(10.2 \%)$ \\
\hline \multicolumn{2}{|l|}{ Vilazodone } \\
\hline Yes & $15(1.0 \%)$ \\
\hline
\end{tabular}


Table 3: Univariate Logistic Regression Analyses: Risk of Bleeding Events in Patients with Blood Factor Clotting Disorders; Risk According to Demographics, Clinical Characteristics and Antidepressant Use

\begin{tabular}{|lll|}
\hline Univariate models & OR $(95 \% \mathrm{CI})$ & P-Value \\
\hline age (continuous) & $1.02(1.01-1.03)$ & $<0.0001$ \\
\hline & & $<0.0001$ \\
\hline Age (categorical) & & \\
\hline 12-25 years old & $0.88(0.50-1.53))$ & \\
\hline 26-45 years old (ref) & 1.00 & \\
\hline 46-65 years old & $1.75(1.23-2.51)$ & \\
\hline 66-91 years old & $3.40(2.27-5.08)$ & \\
\hline & \\
\hline Gender & 1.00 \\
\hline Female (ref) & $1.83(1.40-2.40)$ & \\
\hline Male & \\
\hline & \\
\hline Region & 1.00 \\
\hline Northeast & $0.95(0.62-1.46)$ \\
\hline Midwest & $1.14(0.76-1.71)$ \\
\hline Southeast & $1.05(0.64-1.73)$ \\
\hline Southwest & $0.95(0.58-1.56)$ \\
\hline West & \\
\hline
\end{tabular}


Table 3 continued: Univariate Logistic Regression Analyses: Risk of Bleeding Events in Patients with Blood Factor Clotting Disorders; Risk According to Demographics, Clinical Characteristics and Antidepressant Use

\begin{tabular}{|c|c|c|}
\hline Comorbidities & OR $(95 \% \mathrm{CI})$ & P-Value \\
\hline HIV & & 0.3245 \\
\hline no (ref) & 1.00 & \\
\hline yes & $1.80(0.56-5.80)$ & \\
\hline HEPC & & 0.0695 \\
\hline no (ref) & 1.00 & \\
\hline yes & $2.05(0.94-4.45)$ & \\
\hline Diabetes & & 0.0007 \\
\hline no (ref) & 1.00 & \\
\hline yes & $1.78(1.27-2.49)$ & \\
\hline NSAID Use & & 0.0051 \\
\hline no (ref) & 1.00 & \\
\hline Yes & $1.54(1.14-2.08)$ & \\
\hline Anticoagulant Use & & $<0.0001$ \\
\hline no (ref) & 1.00 & \\
\hline yes & $2.00(1.43-2.78)$ & \\
\hline Antidepressant Class & OR $(95 \% \mathrm{CI})$ & P-Value \\
\hline SSRI or SNRI & & 0.6795 \\
\hline no (ref) & 1.00 & \\
\hline yes & $1.09(0.74-1.60)$ & \\
\hline Hemophilia A & & $<0.0001$ \\
\hline Yes & $2.03(1.52-2.72)$ & \\
\hline Hemophilia B/ C & & 0.7661 \\
\hline Yes & $0.93(0.59-1.47)$ & \\
\hline VWD & & 0.0737 \\
\hline Yes & $0.75(0.54-1.03)$ & \\
\hline $\begin{array}{l}\text { Other Clotting Factors/ } \\
\text { Intrinsic Anticoagulants }\end{array}$ & & 0.4088 \\
\hline Yes & $1.12(0.86-1.45)$ & \\
\hline
\end{tabular}


Table 4: Risk of Bleeding Events According to Demographic, Clinical Characteristics, and Antidepressant Medication Use: Saturated Logistic Regression Model

\begin{tabular}{|c|c|c|}
\hline \multicolumn{3}{|l|}{ Variable } \\
\hline & OR $(95 \% \mathrm{CI})$ & P-Value \\
\hline Age & $1.02(1.01-1.03)$ & $<0.0001$ \\
\hline Gender & & 0.0052 \\
\hline Female & 1.00 & Ref \\
\hline Male & $1.51(1.13-2.00)$ & 0.0052 \\
\hline Region & & 0.9178 \\
\hline Northeast & 1.00 & Ref \\
\hline Midwest & $0.93(0.61-1.42)$ & 0.5867 \\
\hline Southeast & $1.03(0.69-1.54)$ & 0.9146 \\
\hline Southwest & $0.99(0.61-1.62)$ & 0.9881 \\
\hline West & $0.90(0.55-1.47)$ & 0.5981 \\
\hline HIV & $1.19(0.36-3.93)$ & 0.9534 \\
\hline Diabetes & $1.32(0.95-1.84)$ & 0.2599 \\
\hline Hepatitis C & $1.63(0.73-3.61)$ & 0.6878 \\
\hline NSAID Use & $1.56(1.14-2.13)$ & 0.0065 \\
\hline Anticoagulant Use & $1.98(1.40-2.80)$ & $<0.0001$ \\
\hline SSRI or SNRI & $1.00(0.67-1.50)$ & 0.9898 \\
\hline Hemophilia A & $2.37(1.64-3.42)$ & $<0.0001$ \\
\hline Hemophilia B/ C & $1.15(0.70-1.92)$ & 0.5770 \\
\hline VWD & $1.49(0.98-2.26)$ & 0.0625 \\
\hline $\begin{array}{l}\text { Other Clotting Factors/ } \\
\text { Intrinsic Anticoagulants }\end{array}$ & $1.29(0.90-1.85)$ & 0.1610 \\
\hline
\end{tabular}


Table 5: Risk of Bleeding Events According to Demographic, Clinical Characteristics, and Antidepressant Medication Use: Fitted Multivariate Logistic Regression Model

\begin{tabular}{|llr|}
\hline Multivariate models & OR $(95 \% \mathrm{CI})$ & P-Value \\
\hline Age & $1.02(1.02-1.03)$ & $<0.0001$ \\
\hline Male gender & $1.53(1.15-2.02)$ & 0.0031 \\
\hline NSAID Use & $1.66(1.18-2.35)$ & 0.0039 \\
\hline Anticoagulant Use & $2.22(1.55-3.17)$ & $<0.0001$ \\
\hline Hemophilia A & $2.12(1.54-2.93)$ & $<0.0001$ \\
\hline VWD & $1.27(0.88-1.84)$ & 0.2010 \\
\hline SSRI or SNRI Use & $1.02(0.68-1.1)$ & 0.9325 \\
\hline
\end{tabular}




\section{APPENDIX 2: Flow Charts}

Figure 1: Study Sample Selection Flow Chart

Medical Cohort

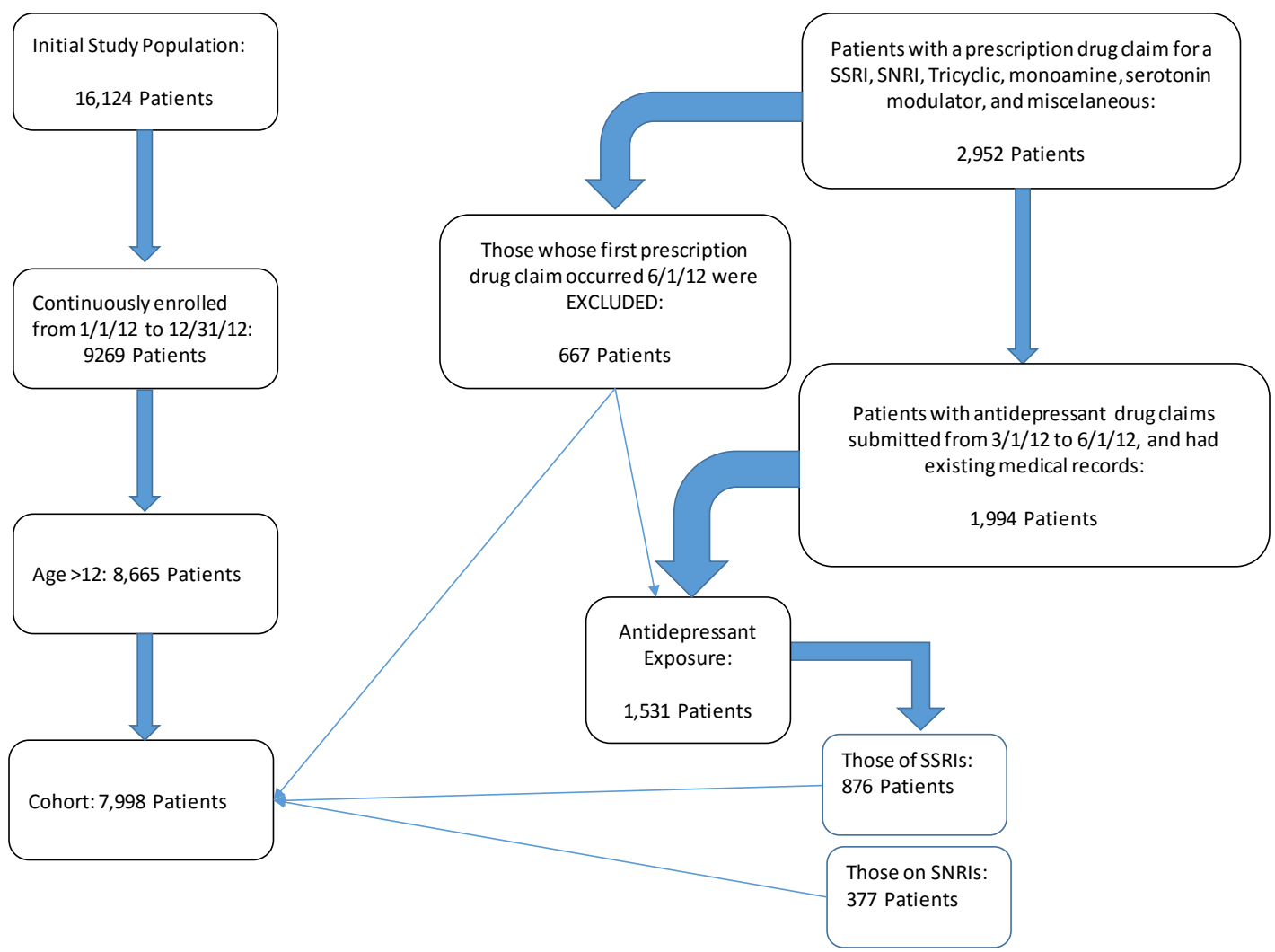

SSRI: Selective Serotonin Reuptake Inhibitor SNRI: Serotonin Norepinephrine Reuptake Inhibitor 
Figure 2: Frequency of Utilization of Antidepressant Medications

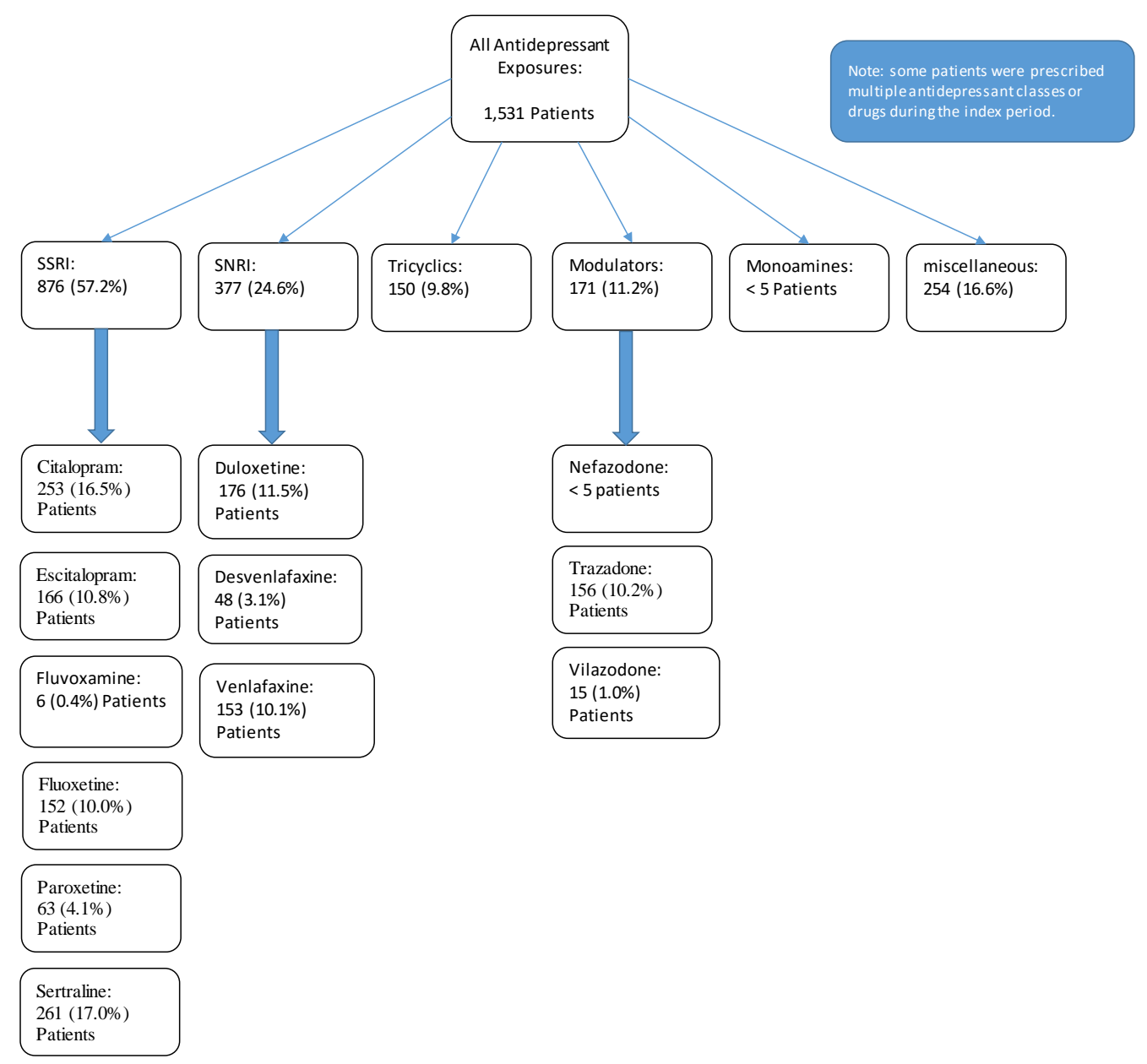


APPENDIX 3: Diagnosis codes for blood clotting disorders, hemorrhages, and drug class codes

\begin{tabular}{|c|c|}
\hline Blood Clotting Factor Disorders & ICD-9 Code \\
\hline Congenital factor VIII disorder (hemophilia A) & 286.0 \\
\hline Congenital factor IX disorder (Hemophilia B) & 286.1 \\
\hline Congenital factor XI deficiency (Hemophilia C) & 286.2 \\
\hline Congenital deficiency of other clotting factors & 286.3 \\
\hline Von Willebrand's disease & 286.4 \\
\hline Hemorrhagic disorder due to intrinsic circulating anticoagulants & 286.5 \\
\hline Antidepressant drug classifications & Optum code \\
\hline Selective Serotonin Reuptake Inhibitor & 28160420 \\
\hline Serotonin Norepinephrine Reuptake Inhibitor & 28160416 \\
\hline Tricyclics & 28160428 \\
\hline Monoamine Oxidase Inhibitors & 28160412 \\
\hline Antidepressants, Miscellaneous & 28160492 \\
\hline Serotonin Modulators & 28160424 \\
\hline Other drugs & Code \\
\hline Anticoagulants, Miscellaneous & 20120492 \\
\hline Heparins & 20120416 \\
\hline Direct Factor Xa Inhibitors & 20120414 \\
\hline Direct Thrombin inhibitors & 20120412 \\
\hline Coumarin Derivatives & 20120408 \\
\hline Cyclooxygenase $=2(\mathrm{COx}-2)$ Inhibitors & 28080408 \\
\hline Salicylates & 28080424 \\
\hline Other NSAIDs Agents & 28080492 \\
\hline Comorbidities & ICD-9 Codes \\
\hline HIV & V08 \\
\hline AIDS & 042 \\
\hline HIV-2 & 07953 \\
\hline Human T-cell lymphotrophic virus, type 1 (HTLV-I) & 07951 \\
\hline HIV counseling & v6544 \\
\hline Acute Hepatitis C with Hepatic Coma & 07041 \\
\hline Chronic Hepatitis C With Hepatic Coma & 07044 \\
\hline Chronic Hepatitis C without Hepatic Coma & 07054 \\
\hline Unspecified Viral Hepatitis C without Hepatic Coma & 07070 \\
\hline Unspecified Viral Hepatitis C with Hepatic Coma & 07071 \\
\hline Diabetes Mellitus w/o mention of complications, Type II, controlled & 25000 \\
\hline Diabetes Mellitus w/o mention of complications, Type I, controlled & 25001 \\
\hline Diabetes Mellitus w/o mention of complications, Type II, uncontrolled & 25002 \\
\hline Diabetes Mellitus w/o mention of complications, Type I, uncontrolled & 25003 \\
\hline
\end{tabular}


APPENDIX 4: Identifying bleeding events using ICD-9 codes for Hemorrhages (25)

\begin{tabular}{|lr|}
\hline description & Code \\
\hline hemopericardium & 423 \\
\hline subarachnoid hemorrhage & 430 \\
\hline intracerebral hemorrhage & 431 \\
\hline Nontraum extradural hem & 432 \\
\hline Subdural hemorrhage & 432.1 \\
\hline Intracranial hemorr NOS & 432.9 \\
\hline int hemrrhoid w comp nec & 455.2 \\
\hline ext hemrrhoid w comp nec & 455.5 \\
\hline hemrrhoid NOS $w$ comp nec & 455.8 \\
\hline hemorrhage NOS & 459 \\
\hline esophag varices $w$ bleed & 456 \\
\hline esoph varices in oth dis & 456.2 \\
\hline mallory-weiss syndrome & 530.7 \\
\hline esophageal disorder nec & 530.8 \\
\hline ac stomach ulcer $w$ hem & 531 \\
\hline ac stomach ulcer $w$ hem-obst & 531.01 \\
\hline ac stomach ulc $w$ hem/perf & 531.2 \\
\hline ac stomach ulc $w$ hem/perf-obst & 531.21 \\
\hline chr stomach ulc $w$ hem & 531.4 \\
\hline chr stomach ulc $w$ hem-obst & 531.41 \\
\hline chr stomach ulc hem/perf & 531.6 \\
\hline chr stomach ulc hem/perf-obst & 531.61 \\
\hline ac duodenal ulcer $w$ hem & 532 \\
\hline ac duodenal ulcer $w$ hem-obst & 532.01 \\
\hline ac duodenal ulc $w$ hem/perf & 532.2 \\
\hline ac duodenal ulc $w$ hem/perf-obst & 532.21 \\
\hline chr duoden ulcer $w$ hem & 532.4 \\
\hline chr duoden ulcer $w$ hem-obst & 532.41 \\
\hline chr duoden ulc $w$ hem/perf & 532.6 \\
\hline chr duoden ulc $w$ hem/perf-obst & 532.61 \\
\hline ac peptic ulc $w$ hemorr & 533 \\
\hline ac peptic ulc $w$ hemorr-obst & 533.01 \\
\hline ac peptic ulc $w$ hem/perf & 533.2 \\
\hline ac peptic ulc $w$ hem/perf-obst & 533.21 \\
\hline chr peptic ulcer $w$ hem & 533.4 \\
\hline chr peptic ulcer $w$ hem-obst & 533.41 \\
\hline chr peptic lc $w$ hem/perf & 533.6 \\
\hline chr peptic lc $w$ hem/perf-obst & 533.61 \\
\hline ac marginal ulcer $w$ hem & 534 \\
\hline ac marginal ulcer w hem-obst & 534.01 \\
\hline
\end{tabular}




\begin{tabular}{|c|c|}
\hline ac margin ulc $\mathrm{w}$ hem/perf & 534.2 \\
\hline ac margin ulc w hem/perf-obst & 534.21 \\
\hline chr marginal ulcer w hem & 534.4 \\
\hline chr marginal ulcer w hem-obst & 534.41 \\
\hline chr marg ulc w hem/perf & 534.6 \\
\hline chr marg ulc w hem/perf-obst & 534.61 \\
\hline acute gastritis with hemorrhage & 535.01 \\
\hline Atrophic gastritis with hemorrhage & 535.11 \\
\hline $\begin{array}{l}\text { gastr mucosoal hypertroph with } \\
\text { hemorrhage }\end{array}$ & 535.21 \\
\hline alcoholic gastritis with hemorrhage & 535.31 \\
\hline gastritis nec with hemorrhage & 535.41 \\
\hline gastritis/duodenitis NOS with hemorrhage & 535.51 \\
\hline duodenitis with hemorrhage & 535.61 \\
\hline gastroduodenal dis nec & 537.8 \\
\hline diverticula sm intestine $w$ hemorrhage & 562.02 \\
\hline diverticulitis sm intestine $\mathrm{w}$ hemorrhage & 562.03 \\
\hline diverticula of colon w hemorrhage & 562.12 \\
\hline diverticulitis of colon w hemorrhage & 562.13 \\
\hline hemoperitoneum & 568.81 \\
\hline rectal and anal hemorrhage & 569.3 \\
\hline angiodysplasia with hem nec & 569.85 \\
\hline hematemesis & 578 \\
\hline blood in stool & 578.1 \\
\hline Gastrointest hemorr NOS & 578.9 \\
\hline renalvascular disorder & 593.81 \\
\hline hematuria & 599.7 \\
\hline noninflam dis vagina nec & 623.8 \\
\hline excessive menstruation & 626.2 \\
\hline metrorrhagia & 626.6 \\
\hline hemarthrosis (nonspecific) & 719.1 \\
\hline hemarthrosis (shoulder) & 719.11 \\
\hline hemarthrosis (upper arm) & 719.12 \\
\hline hemarthrosis (forearm) & 719.13 \\
\hline hemarthrosis (hand) & 719.14 \\
\hline hemarthrosis (pelvis) & 719.15 \\
\hline hemarthrosis (leg) & 719.16 \\
\hline hemarthrosis (ankle) & 719.17 \\
\hline hemarthrosis (joint, neck) & 719.18 \\
\hline epistaxis & 784.7 \\
\hline Hemorrhage from throat & 784.8 \\
\hline hemoptysis & 786.3 \\
\hline
\end{tabular}


APPENDIX 5: IRB exempt approval

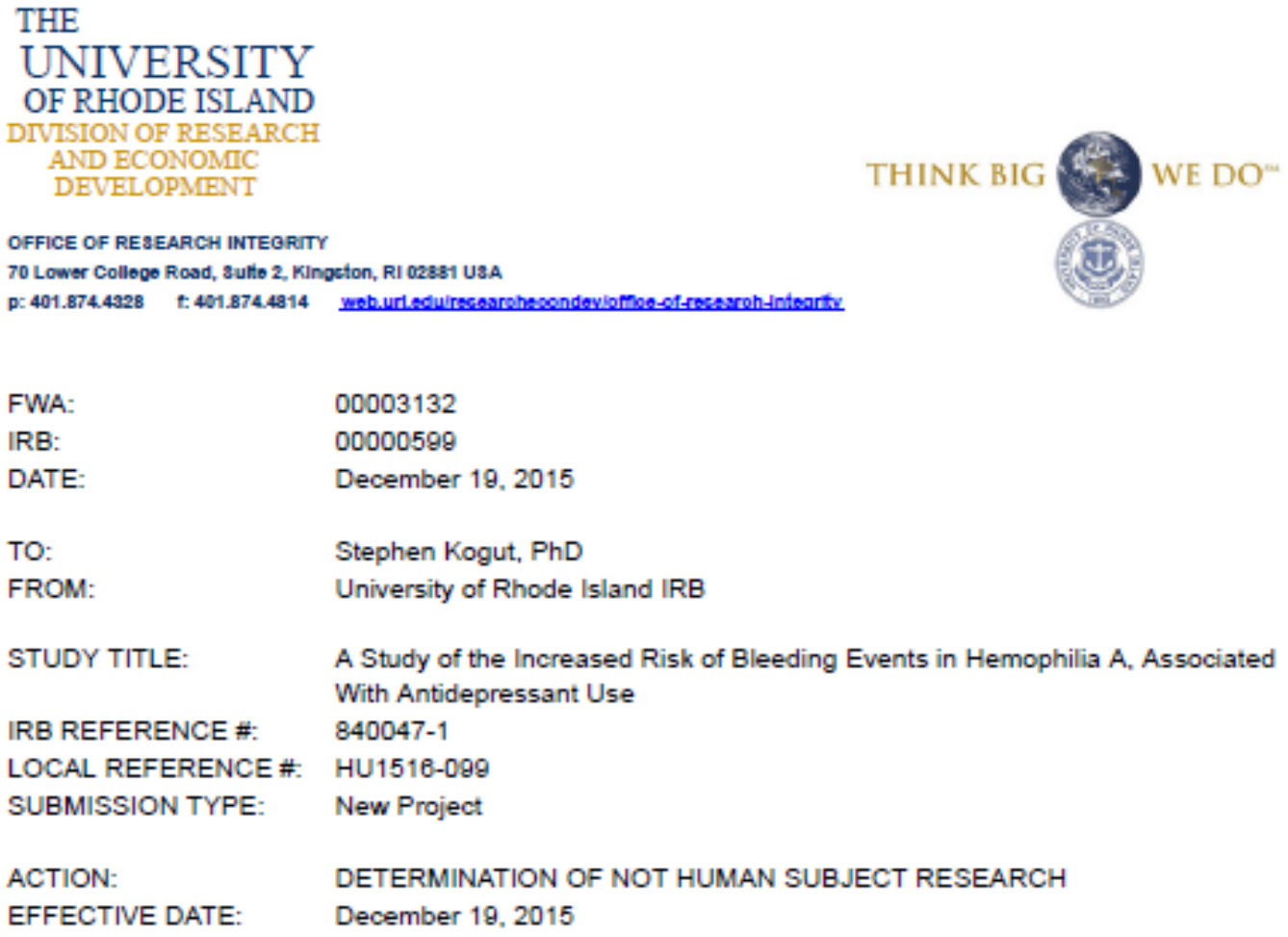

Thank you for your submission of New Project materials for this research study. The University of Rhode Island IRB has determined this project does not meet the definition of human subject research under the purview of federal regulation 45 CFR 46 regarding human subject research at this time. Therefore, your project does not require Institutional Review Board (IRB) oversight. Any changes in focus of this project will require further review of the IRB.

If you have any questions, please contact us by email at researchintegrity@etal.uri.edu. Please include your study title and reference number in all correspondence with this office.

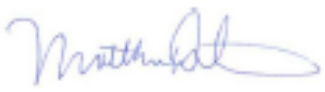

Matthew Delmonico, Ph.D., MPH IRB Chair 


\section{Bibliography}

1. The Blood Coagulation Process [Internet]. rnceus.com; ND [cited 3/20/2016]. Available from: http://www.rnceus.com/coag/coagpro.html.

2. Soucie JM, Evatt B, Jackson D. Occurrence of hemophilia in the United States. Am J Hematol. 1998;59(4):288-94.

3. Rodeghiero F, Castaman G, Dini E. Epidemiological investigation of the prevalence of von Willebrand's disease. Blood. 1987 American Society of Hematology;69(2):454-9.

4. Hemophilia A [Internet]. Hemophilia.org: National Hemophilia Foundation; ND [cited 3/20/2016]. Available from: https://www.hemophilia.org/Bleeding-Disorders/Types-ofBleeding-Disorders/Hemophilia-A.

5. Stone K, Viera A, Parman C. Off-label Applications for SSRIs. American Family Physicians. 2003;68:498-504.

6. Pratt L, Brody D, Gu Q. Antidepressant use in persons aged 12 and over: United States, 2005-2008. NCHS. 2011(76):1-8.

7. Iannone M, Pennick L, Tom A, Cui H, Gilbert M, Weihs K, et al. Prevalence of depression in adults with haemophilia. Haemophilia. 2012;18(6):868-74.

8. Pirraglia PA, Stafford RS, Singer DE. Trends in Prescribing of Selective Serotonin Reuptake Inhibitors and Other Newer Antidepressant Agents in Adult Primary Care. Prim Care Companion J Clin Psychiatry. 2003 Aug;5(4):153-7.

9. Turner MS, May DB, Arthur RR, Xiong GL. Clinical impact of selective serotonin reuptake inhibitors therapy with bleeding risks. J Intern Med. 2007;261(3):205-13.

10. Sussman N. Medical Complications of SSRI and SNRI Treatment. PP [Internet]. 2008 02/01/2008 [cited 03/20/2016]:03/20/2016. Available from: http://primarypsychiatry.com/medical-complications-of-ssri-and-snri-treatment/.

11. PRODAN CI, JOSEPH PM, VINCENT AS, DALE GL. Coated-platelet levels are influenced by smoking, aspirin, and selective serotonin reuptake inhibitors. Journal of Thrombosis and Haemostasis. 2007;5(10):2149-51.

12. Ewenstein BM. Von Willebrand's disease. Annu Rev Med. 1997;48:525-42.

13. James PD, Goodeve AC. von Willebrand Disease. Genetics in medicine : official journal of the American College of Medical Genetics. 2011 05;13(5):10.1097/GIM.0b013e3182035931.

14. SILWER J, NILSSON IM. On a Swedish Family with 51 Members Affected by von Willebrand's Disease. Acta Med Scand. 1964;175(5):627-43. 
15. Larrieu MJ, Caen JP, Meyer DO, Vainer H, Sultan Y, Bernard J. Congenital bleeding disorders with long bleeding time and normal platelet count. II. Von Willebrand's disease (report of thirty-seven patients). Am J Med. 1968 Sep;45(3):354-72.

16. Holmberg L, Nilsson IM. von Willebrand's disease. Eur J Haematol. 1992;48(3):12741.

17. Fressinaud E, Meyer D. International survey of patients with von Willebrand disease and angiodysplasia. Thromb Haemost. 1993 Sep 1;70(3):546.

18. Plug I, Mauser-Bunschoten EP, Bröcker-Vriends AHJT, van Amstel HKP, van der Bom JG, van Diemen-Homan JEM, et al. Bleeding in carriers of hemophilia. Blood. 2006 American Society of Hematology;108(1):52-6.

19. Flood E, Pocoski J, Michaels LA, McCoy A, Beusterien K, Sasanè R. Patientreported experience of bleeding events in haemophilia. Eur J Haematol. 2014;93:19-28.

20. Dawson AL, Ailes EC, Gilboa SM, et al. Antidepressant Prescription Claims Among Reproductive-Aged Women With Private Employer-Sponsored Insurance — United States 2008-2013. MMWR Morb Mortal Wkly. 2016.

21. Quinn GR, Singer DE, Chang Y, Go AS, Borowsky LH, Udaltsova N, et al. Effect of Selective Serotonin Reuptake Inhibitors on Bleeding Risk in Patients With Atrial Fibrillation Taking Warfarin. Am J Cardiol 2016/04;114(4):583-6.

22. Hougardy DM, Egberts TC, van der Graaf F, Brenninkmeijer VJ, Derijks LJ. Serotonin transporter polymorphism and bleeding time during SSRI therapy. Br J Clin Pharmacol. 2008 May;65(5):761-6.

23. Barlow JH, Stapley J, Ellard DR. Living with haemophilia and von Willebrand's: A descriptive qualitative study. Patient Educ Couns. 2007 11;68(3):235-42.

24. Hajian-Tilaki K. Sample size estimation in epidemiologic studies. Caspian Journal of Internal Medicine. 2011 09/10;2(4):289-98.

25. Arnason T, Wells PS, van Walraven C, Forster AJ. Accuracy of coding for possible warfarin complications in hospital discharge abstracts. Thromb Res. 2006;118(2):253-62.

26. 5 Regions of the United States [map]. http://www.spangledwithstars.com/us-statemaps/5-regions-map-united-states.htm: .

27. Kutner MH, Nachtsheim CJ, Neter J. Applied Linear Regression Models (4th ed.). McGraw-Hill Irwin; 2004.

28. EYSTER ME, GAIL MH, BALLARD JO, AL-MONDHIRY H, GOEDERT JJ. Natural History of Human Immunodeficiency Virus Infections in Hemophiliacs: Effects 
of T-Cell Subsets, Platelet Counts, and Age. Annals of Internal Medicine. 1987 July $1 ; 107(1): 1-6$.

29. Eyster ME, Diamondstone LS, Lien JM, Ehmann WC, Quan S, Goedert JJ. Natural history of hepatitis $\mathrm{C}$ virus infection in multitransfused hemophiliacs: effect of coinfection with human immunodeficiency virus. The Multicenter Hemophilia Cohort Study. J Acquir Immune Defic Syndr. 1993 Jun;6(6):602-10.

30. Inwood M, Killackey B, Startup S. The use and safety of Ibuprofen in the hemophiliac. Blood. 1983;61(4):709-11.

31. EYSTER ME, ASAAD SM, GOLD BD, COHN SE, GOEDERT JJ, THE SECOND MULTICENTER HEMOPHILIA STUDY GROUP. Upper gastrointestinal bleeding in haemophiliacs: incidence and relation to use of non-steroidal anti-inflammatory drugs. Haemophilia. 2007;13(3):279-86.

32. Witmer C, Presley R, Kulkarni R, Michael Soucie J, Manno CS, Raffini L. Associations between intracranial haemorrhage and prescribed prophylaxis in a large cohort of haemophilia patients in the United States. Br J Haematol. 2011;152(2):211-6.

33. Hylek EM, Held C, Alexander JH, Lopes RD, De Caterina R, Wojdyla DM, et al. Major Bleeding in Patients With Atrial Fibrillation Receiving Apixaban or WarfarinThe ARISTOTLE Trial (Apixaban for Reduction in Stroke and Other Thromboembolic Events in Atrial Fibrillation): Predictors, Characteristics, and Clinical Outcomes. Journal of the American College of Cardiology. 2014 May 27;63(20):2141-7.

34. Castro VM, Gallagher PJ, Clements CC, Murphy SN, Gainer VS, Fava M, et al. Incident user cohort study of risk for gastrointestinal bleed and stroke in individuals with major depressive disorder treated with antidepressants. BMJ Open. $2012 \mathrm{Mar}$ 30;2(2):e000544,2011-000544. Print 2012.

35. Hackam DG, Mrkobrada M. Selective serotonin reuptake inhibitors and brain hemorrhage: a meta-analysis. Neurology. 2012 Oct 30;79(18):1862-5. 